Portland State University

PDXScholar

Spring 5-19-2017

\title{
Let the Seeds Fall Where They May: Investigating the Effect of Landscape Features on Fine-Scale Seed Dispersal
}

Monica R. Grasty

Portland State University

Follow this and additional works at: https://pdxscholar.library.pdx.edu/open_access_etds

Part of the Biology Commons, and the Botany Commons Let us know how access to this document benefits you.

\section{Recommended Citation}

Grasty, Monica R., "Let the Seeds Fall Where They May: Investigating the Effect of Landscape Features on Fine-Scale Seed Dispersal" (2017). Dissertations and Theses. Paper 4001.

https://doi.org/10.15760/etd.5885

This Thesis is brought to you for free and open access. It has been accepted for inclusion in Dissertations and Theses by an authorized administrator of PDXScholar. Please contact us if we can make this document more accessible: pdxscholar@pdx.edu. 
Let the Seeds Fall Where They May:

Investigating the Effect of Landscape Features on Fine-Scale Seed Dispersal

by

Monica Rosalie Grasty

A thesis submitted in partial fulfillment of the requirements for the degree of

Master of Science

in

Biology

Thesis Committee:

Mitch Cruzan, Chair

Sarah Eppley

Susan Masta

Portland State University

2017 


\begin{abstract}
Seed dispersal is a crucial ecological and evolutionary process that allows plants to colonize sites and expand their ranges, while also reducing inbreeding depression and facilitating the spread of adaptive genetic variation. However, our fundamental understanding of seed dispersal is limited due to the difficulty of directly observing dispersal events. In recent years, genetic marker methods have furthered our understanding of colonization and range expansion due to seed dispersal. Most investigations focus on regional scales of dispersal, due to low levels of variation in the chloroplast genome (cpDNA), which can serve as an indirect measure of seed dispersal. Here, I employ a whole-genome assay of cpDNA variation in Plagiobothrys nothofulvus to resolve variation due to patterns of seed dispersal within a 400x400 meter section of the Whetstone Savanna Preserve in Central Point, OR, USA. Whetstone is characterized by a mosaic of habitat types, including vernal pools, hummocks of dry prairie, and large Ceanothus cuneatus bushes, as well as a network of vole runways. Plagiobothrys nothofulvus grows in dense patches on hummocks within this prairie.

I found evidence of limited seed dispersal in P. nothofulvus, indicated by strong genetic structure over distances of less than 100 meters. There was little evidence that geographic distance predicts genetic distance; environmental features have a stronger influence on dispersal. Habitat preference was the strongest predictor of genetic variation in $P$. nothofulvus, indicating that it may be a habitat specialist in this prairie. Flower density also accounted for a significant portion of dispersal, which may be a consequence of the annual life history of $P$. nothofulvus resulting in seasonal turnover and lack of
\end{abstract}


competition with adult plants. Least-cost-path analysis indicated that seeds are secondarily dispersed by small mammals along vole runways. Overall, I found significant evidence that landscape features influence dispersal, even at a very fine spatial scale. 


\section{Acknowledgments}

During the time that I have spent working on my thesis, from the exhausting hours spent collecting leaf tissue in the field, to the process of actually writing down what I did, there have been a few key people in my life providing endless support and guidance. As long as I have wanted to pursue graduate school, any self-doubt about my own ability has been met with an equal and opposite reaction of encouragement from my network of allies.

As early as I can remember, my family has been nurturing my love of science. I love recounting the story of filling out my copy of Dr. Seuss's "My Book About Me by Me Myself" that my parents gave me for Christmas when I was five or six, getting to the question about what I want to be when I grow up, and asking my mom what a person who studies the ocean is called. That was the first time I heard the word "biologist," and although I don't study the ocean now, I still draw from the same passion I felt when I was a child. As I grew, my passion for science took new forms; sometimes digging up the yard collecting pill bugs, or raiding the local Hollywood Video for nature documentaries. My parents have been on-board from the start, and I want to thank them for that. My sister, Samantha, has also played a large part in my success. She has been many things to me throughout my life: a playmate, a roommate, someone to argue with, my best friend. She has been there for me at times in when I have felt most unsure, and helped give me tools to support myself during my most difficult moments. Thank you, sister.

More recently, I have felt immense support from the Cruzan lab at Portland State. Mitch Cruzan, my advisor, has created an atmosphere in the lab where collaboration is a given, encourages his students to pursue their own ideas, and challenges us to try things 
we may be unsure of. He saw potential in me as a researcher, and pushed me to try new things that made my research interesting, innovative, and relevant. Pam Thompson has been similarly essential during my time at Portland State. As a postdoctoral researcher on the project that my thesis is a part of, she helped me find new perspective in my research questions. As a friend, Pam has been a key source of support in moments when I have been most emotionally stressed, grad school related or otherwise. As a whole, the collaborative effort that characterizes the Cruzan lab has been a key resource in my thesis research - Tina Arredondo, Brendan Kohrn, Jaime Schwoch, Lizzi Hendrickson, Jessica Persinger, and Avery Pheil have all provided their own insight and helped inspire the work in my thesis research, and I cannot thank them enough for that.

For just over a year, I have had the best ally I could ask for: my boyfriend, Taylor Rose. We met while we were both in the throes of graduate school - he was working on his Master's degree in environmental history, which he has since completed. Because we were both at similar places in our research at the time, we found common ground in many aspects of our scholarship, and bonded over a shared passion for knowledge. Taylor recognizes the parts of myself that I am most proud of, and encourages me to explore my own passions. Witnessing his zeal for history reminded me of what excites me about plant biology, and gave new life to my own research.

As I complete this chapter in my life, I cannot help but feel a debt of gratitude to the people who inspired and encouraged me along the way. During the years I have been working on this research, I learned the value in asking more questions, giving myself bigger challenges, and finding new passion in my research every day, all of which could not have happened without the encouragement of my family, colleagues, and partner. 


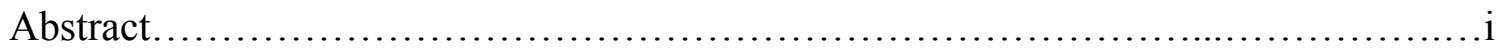

Acknowledgments.........................................................ii

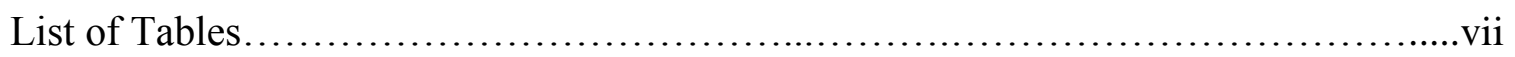

List of Figures.......................................................... viii

Introduction................................................................

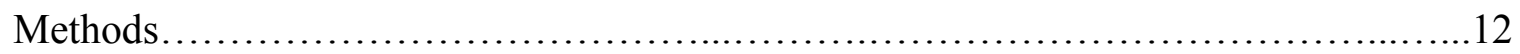

Sampling Design.................................................... 12

Genetic Analysis................................................... 13

UAV Surveys and Circuit Resistance Maps..............................16

Dispersal Model Selection..................................................21

Results...................................................................23

Haplotype Genetic Structure..........................................23

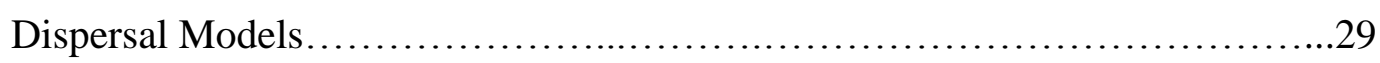

Discussion................................................................ 31

Conclusions.............................................................. 37

References.............................................................. 38

Appendices

A. Pairwise Edwards' chord genetic distance matrix.......................43

B. Pairwise geographic distance matrix..............................44

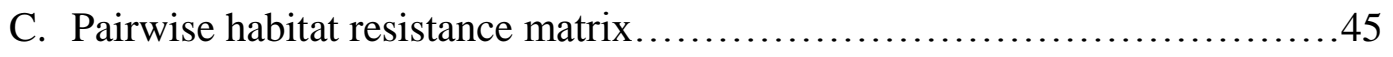

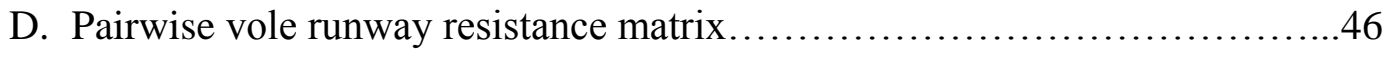


E. Pairwise flower density resistance matrix............................47

F. Pairwise habitat/flower density resistance matrix......................48

G. Pairwise habitat/vole runway resistance matrix........................49

H. Pairwise vole runway/flower density resistance matrix....................50

I. Pairwise least-cost-path vole runway matrix...........................51 


\section{List of Tables}

Table 1: Average genetic distance within and among clusters.........................26

Table 2: MRDM and Mantel test model selection results...........................28 


\section{List of Figures}

Fig. 1: Sampling locations within Whetstone Savanna Preserve.........................

Fig. 2: Resistance surface maps for landscape variables...........................

Fig. 3: Habitat map showing $P$. nothofulvus flower density $\ldots \ldots \ldots \ldots \ldots \ldots \ldots \ldots \ldots \ldots \ldots$

Fig. 4: General clustered sampling design .......................................... 13

Fig. 5: Orthomosaic and Digital Surface Model................................... 18

Fig. 6: Haplotype genetic structure across Whetstone.............................24

Fig. 7: Cumulative current maps for landscape variables...........................27 
Introduction

Plants depend on seed dispersal to colonize new sites and expand their ranges. Dispersal also facilitates gene flow, which can enable the spread of new adaptations and reduce inbreeding depression within populations (Garant, Forde, \& Hendry, 2007; Slatkin, 1987). Despite its importance for evolution and ecology, our understanding of seed dispersal is very limited due to the difficulty of directly observing and quantifying dispersal events. The ecological significance of seed dispersal has been recognized for decades, but methodological difficulties hamper our ability to completely understand processes and modes of dispersal (Howe \& Smallwood, 1982). Although direct observation of seed dispersal is difficult, genetic markers can provide an indirect measure of the effects of seed dispersal on population genetic structure, and can reveal key insights about factors contributing to range expansion and colonization (Cain, Milligan, \& Strand, 2000; Ouborg, Piquot, \& Van Groenendael, 1999). Most modern investigations of seed dispersal focus on dispersal on a regional scale and employ molecular markers rather than relying on direct observation of dispersal in the field (Wang \& Smith, 2002). These studies typically highlight historic dispersal events and phylogeography rather than modern dispersal. For example, studies using restriction fragment length polymorphisms (RFLPs) typically detect low levels of cpDNA variation, which is inadequate for resolving genetic variation at a fine spatial scale (less than one kilometer) (Antonovics, Thrall, Jarosz, \& Stratton, 1994; Jordan, Courtney, \& Neigel, 1996; Maskas \& Cruzan, 2000). Here, I employ a whole-genome assay of chloroplast DNA (cpDNA) variation using targeted capture to identify larger numbers of variable base positions (Cronn et al., 
2008; Stull et al., 2013), which can reveal insights concerning the processes and mechanisms responsible for seed dispersal at a much finer spatial scale.

The effects of dispersal on population genetic structure can be understood under a model of Isolation-By-Distance (IBD). Under IBD, local gene flow promotes genetic similarity among neighboring populations and similarity declines for populations separated by greater geographic distances (Wright, 1943). Isolation-By-Distance assumes that distribution of genetic variation among populations at neutral loci is a product of two competing factors; gene flow and genetic drift. As dispersal increases, so does gene flow. Additionally, as population size decreases, the effect of genetic drift increases. The dynamics of these two processes working together will ultimately determine genetic similarity among populations of a species (Hutchison \& Templeton, 1999). As gene flow is determined by dispersal these processes may be mediated by ecological factors; landscape features can play a key role in governing seed dispersal rates among populations (Hanski, 1998).

The goal of landscape genetics is to understand the influence of landscape features on patterns of gene flow (Manel, Schwartz, Luikart, \& Taberlet, 2003). Wright's theory of IBD assumes that populations are unbounded and occur in a homogeneous matrix; however, almost any real-world population will violate these assumptions, in turn greatly reducing the accuracy of IBD analyses (McRae \& Nürnberger, 2006). To address these shortcomings, Isolation-By-Resistance (IBR) modeling accounts for the effect of a heterogeneous landscape by calculating overall dispersal resistance across landscape features with varying resistances to dispersal. Isolation-by-resistance modeling is especially helpful in populations that have limited dispersal and/or a fragmented 
distribution - a condition that is becoming more frequent with increasing levels of human disturbance. The key difference between IBR and IBD is that the "easiest" dispersal route between two populations may not be the shortest geographic distance between them. Rather, the ideal path between populations should consider habitat and dispersal barriers, which may result in a less direct route than the shortest geographic distance between them.

One method of IBR modeling uses circuit theory to calculate landscape resistance between pairs of populations by treating gene flow as a charge moving across a landscape of resistors. Circuitscape, a Python-based program and plugin for ArcGIS, can perform these calculations as applied to real-world scenarios (McRae \& Nürnberger, 2006). This program generates pairwise current values that reflect a landscape of varying resistances among populations (Shah \& McRae, 2008). Circuitscape is unique in that it integrates many possible pathways in its calculation of dispersal distance, while Least Cost Path (LCP) modeling (another form of resistance modeling) only shows the single best route option (McRae \& Beier, 2007). Because of this, LCP will outperform Circuitscape's migration predictions in studies where individuals are dispersing predictably though established routes (McClure, Hansen, \& Inman, 2016). In plants, the logical extension of this idea is that directed seed dispersal along established routes (e.g. dispersal along rivers or though feces of migrating animals; e.g. Wenny, 2001) would likely be better suited to LCP modeling. However, for cases in which there is no apparent dispersal vector or if dispersal is limited, Circuitscape is often a more robust method of dispersal prediction (McClure, Hansen, \& Inman, 2016). 
Seed dispersal is often affected by the movement of dispersal vectors through the landscape (Fant, Havens, Keller, Radosavljevic, \& Yates, 2014) and can be limited by microhabitat requirements for plant growth (Andrew, Ostevik, Ebert, \& Rieseberg, 2012; McRae \& Beier, 2007; Yu et al., 2015), which creates unique challenges and advantages for IBR modeling. In animals, choices made by individuals determine the exchange of migrants across a landscape, such as in migratory patterns of elk (e.g., McClure et al., 2016). In plants, on the other hand, the resistance of a landscape is determined by how the vegetation and geographic features influence the behavior of the dispersal vector(s), as well as how well propagules can grow and reproduce in different habitats. For example, dispersal kernels in bird-dispersed plant species were shaped more strongly by fruit resource availability, a dispersal vector choice, than by physical connectivity among populations (Herrmann et al., 2016). The influence of the landscape on seed dispersal has been demonstrated in dune sunflowers, where adaptation to dune habitat acted as an adaptive barrier to gene flow across low-quality habitat (Andrew et al., 2012). Plants are well suited for studies of IBR modeling because they cannot "choose" how they move through a landscape; rather, plants are subject to whatever may be dispersing their pollen and seeds.

As a molecular marker, cpDNA is ideal for investigations of seed dispersal. Because chloroplasts are almost strictly maternally inherited in most plant species (C. W. Birky, 1995; Ellis, Bentley, \& McCauley, 2008; Zhang, 2010), genetic distance estimates based on variation in chloroplast genomes (cpDNA) provide a measure of maternal relatedness among populations, and can act as an indirect measure of seed dispersal (McCauley, 1995). This is true for cytoplasmic genetic markers (mitochondrial and 
chloroplast DNA) for most species, so uncovering variation in cytoplasmic markers is essential for estimating seed dispersal (Cain et al., 2000; McCauley, 1994). Previous studies using cpDNA markers have generally found low variation (Antonovics et al., 1994; Jordan et al., 1996; Maskas \& Cruzan, 2000), which can limit the accuracy of estimates of genetic structure. This low variability can be resolved, however, using a whole-genome targeted capture of cpDNA variation, which can identify higher numbers of variable base positions than conventional cpDNA marker methods (Cronn et al., 2008; Stull et al., 2013).

In applications of resistance modeling, the effect of landscape features on dispersal may depend on the size, life history, and distribution of the study organism. To accurately capture the effect of specific landscape features on dispersal and gene flow, there must be adequate genetic variation between sampling sites. The spatial scale at which this variation can be successfully quantified largely depends on the life history of the species of interest (Anderson et al., 2010). For organisms with greater dispersal potential, such as large trees, variation may only be detectable at a large spatial scale, on the order of several kilometers. The variation observed at larger spatial scales may also be best explained by mutation rates, rather than dispersal, due to limited dispersal between populations at this scale (Nathan \& Muller-Landau, 2000). Conversely, the distribution of variation at smaller spatial scales will be largely dominated by dispersal, rather than mutation, because dispersal rates between populations are typically much higher at smaller spatial scales. However, in small herbaceous annuals that usually disperse seeds over much shorter distances, variation due to mutation may be detectable at a smaller spatial scale. 
When considering IBR, the habitat matrix becomes an important factor in determining the appropriate spatial scale at which to sample. If sites are separated by low-quality habitat, variation may be detectable at a much smaller spatial scale than the life history of the species may suggest. For example, large trees in populations separated by a high-resistance landscape show much greater variation at a smaller spatial scale than one would expect (Dyer, Chan, Gardiakos, \& Meadows, 2012). This is true for species with shorter dispersal distances as well, where low-quality habitat features (features that inhibit dispersal) become barriers to dispersal at much smaller spatial scales.

I conducted a test of landscape features on seed dispersal of the annual plant Plagiobothrys nothofulvus A. Gray (Boraginaceae) within Whetstone Savanna Preserve (Central Point, Oregon, USA). Seeds of this plant are found in nutlets borne in groups of up to four along the stem, and appear to be dispersed primarily by gravity, but may be moved by secondary vectors such as birds and mammals. This is an ideal system for the study of fine-scale landscape genetics because of the unique habitat heterogeneity of Whetstone (Fig. 1), as well as the apparently limited dispersal ability of $P$. nothofulvus. The site is characterized by a mosaic of vernal pools, hummocks of dry prairie, large Ceanothus cuneatus bushes, and scattered oaks (Quercus garryana). Whetstone supports many native prairie and vernal pool plants, including California goldfields (Lasthenia californica), blow-wives (Achyrachaena mollis), southern Oregon buttercup (Ranunculus austro-oreganus), and rusty popcorn flower (Plagiobothrys nothofulvus). 


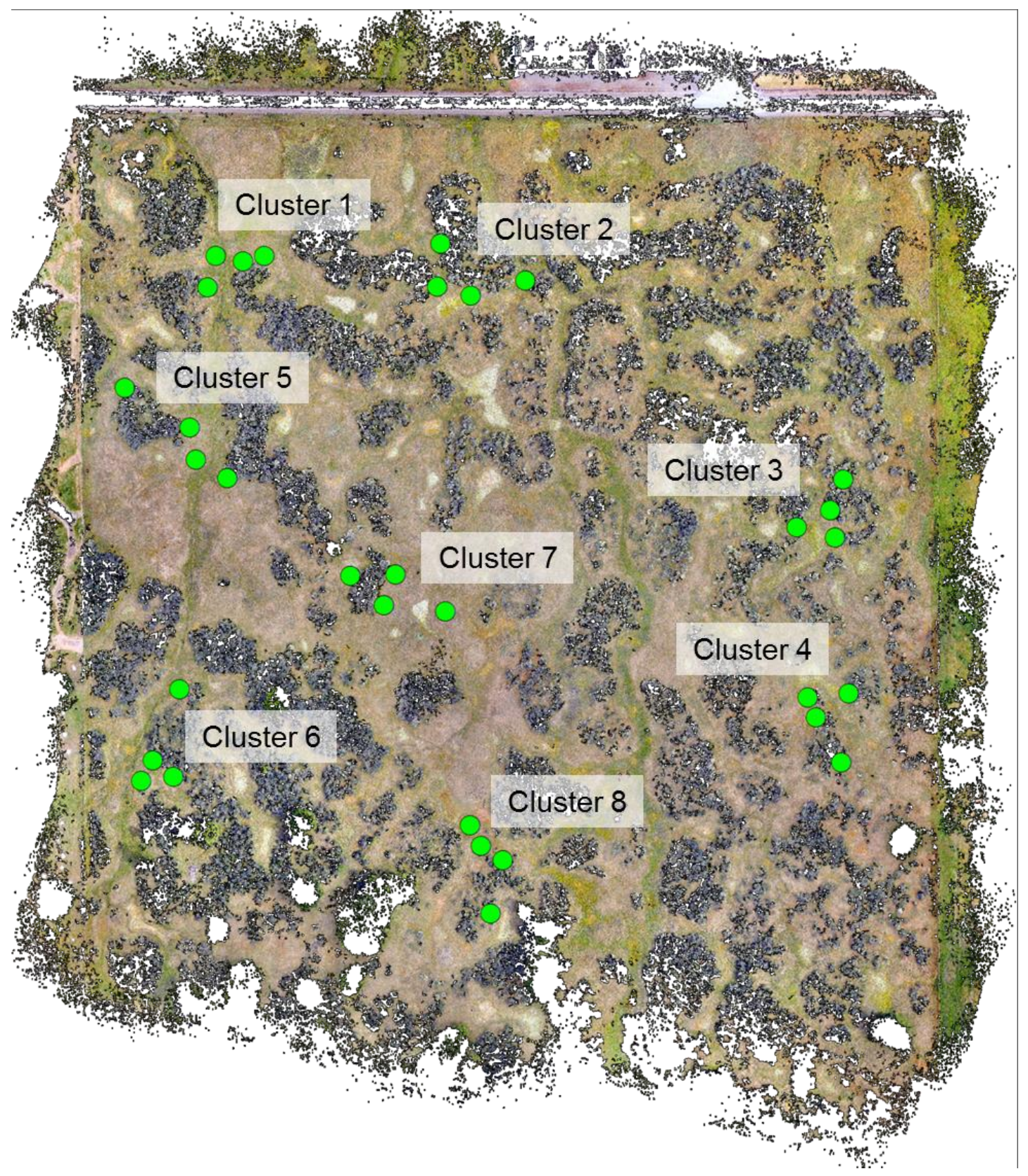

Fig. 1: Sampling locations within Whetstone Savanna Preserve. Samples were collected at eight clusters with four locations within each cluster for a total of 32 sub-populations.

Species with limited dispersal will likely display more genetic differentiation over shorter distances compared to species with more effective dispersal, and I predict that $P$. nothofulvus may be one of these dispersal-limited species. This genus has been included 
in some general studies of the prairies it inhabits (Brown \& Human, 1997; Ingham \& Wilson, 1999; Taylor \& Santelmann, 2014), but no study has previously investigated its dispersal capabilities. This species makes for an especially intriguing system for studying dispersal partly because it tends to only grow on dry prairie hummocks within Whetstone, and may be a habitat specialist for upland prairie. Additionally, the mosaic of habitat types within Whetstone can be assigned discrete resistance values, and in turn provide a test of the effect that this unique landscape has on seed dispersal (Fig. 2A). Another notable physical characteristic of Whetstone is the network of vole runways that intersect swales, hummocks, and bushes throughout the prairie (Fig. 2B), and appear to be temporally stable. These runways represent pathways for the movement of the California vole, Microtus californicus, to feeding areas. The network of runways may represent a type of secondary directed dispersal, where voles, as well as other rodents, might be moving along these runways and dispersing seeds that happen to be near them. Secondary seed dispersal by rodents is relatively common (Forget \& Milleron, 1991; Hoshizaki, Suzuki, \& Sasaki, 1997; Jensen \& Nielsen, 1986; Vander Wall, Kuhn, \& Beck, 2005), and may be important for the dispersal of seeds within the Whetstone prairie. 

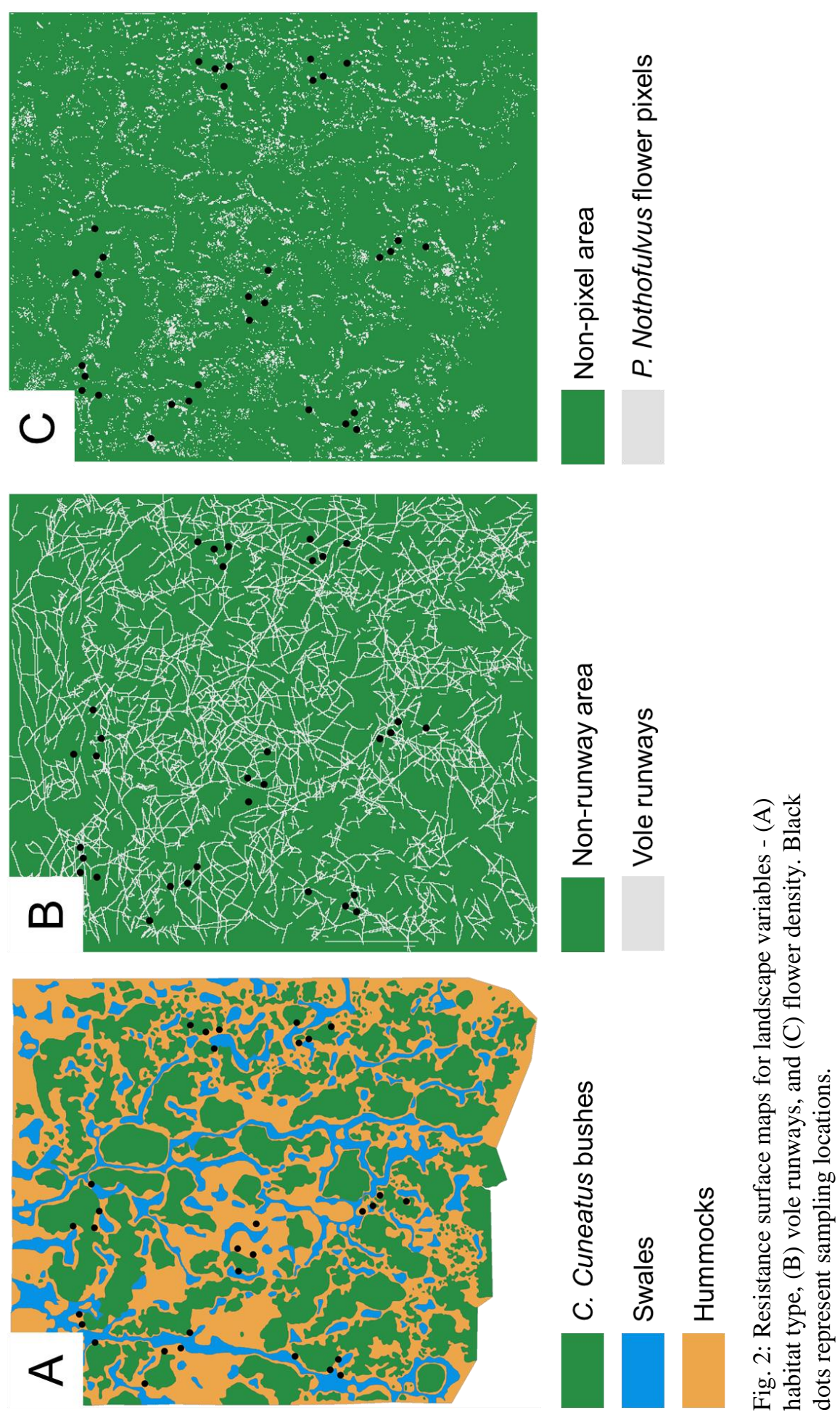
Plant density may reflect the microhabitat conditions for P. nothofulvus and may influence seed-mediated gene flow. Areas of high density represent sites in which this species can survive and reproduce, but the relative density of an area may also reflect the unique resistance of the landscape that a more general classification of habitat cannot describe (Gotelli \& Simberloff, 1987). Even though P. nothofulvus thrives on hummocks of dry prairie, it does not grow homogenously across entire hummocks (Fig. 3). The smaller patches of $P$. nothofulvus populations within the hummock habitat may reflect the species' microhabitat requirements more accurately than simply categorizing entire hummocks as homogeneous habitats.

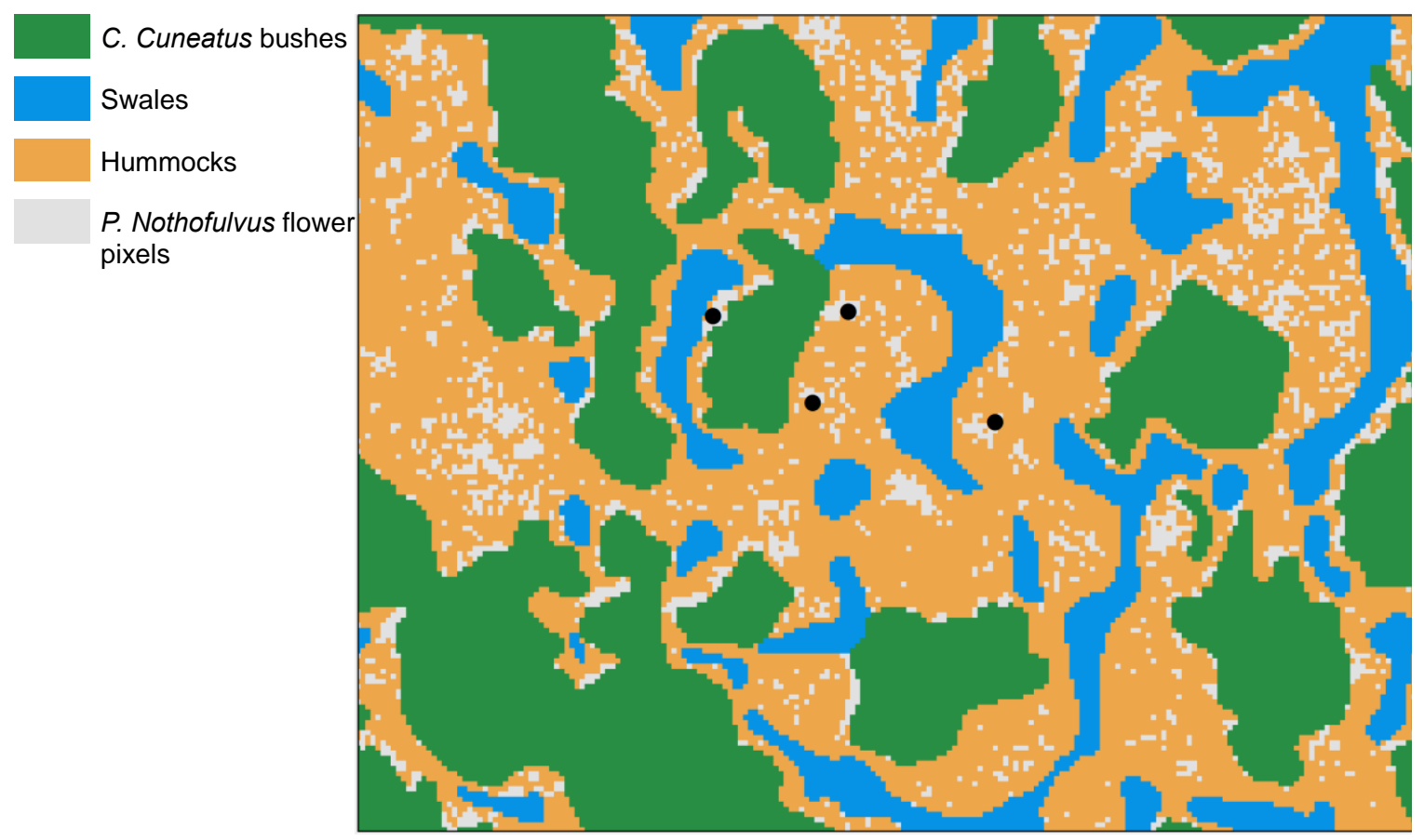

Fig. 3: Habitat map showing $P$. nothofulvus flower density. Black dots represent sampling points.

In this study, I investigate landscape variables that influence the movement of $P$. nothofulvus seeds over a fine spatial scale. Specifically, I address three questions concerning seed dispersal: 1) how much seed-mediated gene flow is occurring among patches of $P$. nothofulvus within this prairie? 2) Does geographic distance predict genetic 
distance? And 3) which, if any, physical features of the landscape influence seed dispersal - habitat heterogeneity, vole runways, or plant density? I predict that there will be quantifiable effects of gene flow within this small prairie; specifically, that geographic distance will be a predictor of genetic distance (IBD), but gene flow may also be influenced by landscape features (IBR). To estimate haplotype frequencies and genetic distances among patches across the Whetstone prairie, I assay whole chloroplast genome variation for $P$. nothofulvus. I conduct multiple regression and permutation analyses on genetic and landscape resistance distance matrices to infer likely dispersal vectors and habitat features that may facilitate or impede seed dispersal. 
Methods

\section{Sampling Design}

In April 2015, I collected samples of $P$. nothofulvus leaf tissue within the Whetstone Savanna Preserve. Whetstone is a 150 -acre The Nature Conservancy site located in Central Point, Oregon in Jackson County $\left(42^{\circ} 25^{\prime} \mathrm{N}, 122^{\circ} 54^{\prime} \mathrm{W}\right)$, and my study site is a 400x400 meter area located in its northernmost part. I sampled 32 sites within the prairie, separated into eight clusters of four sampling locations (Fig. 1). Sampling locations were placed such that the three habitat features that characterize Whetstone separated the four sampling locations within each cluster. These included dry prairie hummocks, vernal pools, and C. cuneatus hedges. At each sampling point, I collected leaf tissue from 20 individuals within approximately four-square meters of dry hummock. The initial collection site (site A) was chosen by locating a hummock flanked by both a vernal pool and a large patch of bushes, with another hummock flanking the pool and bushes on the other side of these features (Fig. 4). Collection site B was located 10-15 meters from site A on the same hummock. Collection site $\mathrm{C}$ was located on a hummock separated from site A by a vernal pool, and site D samples were collected on a hummock separated from site A by C. cuneatus hedges. As I collected leaf tissue, I placed it in coin envelopes in plastic zip-top bags with silica gel to preserve the tissue through dehydration. 


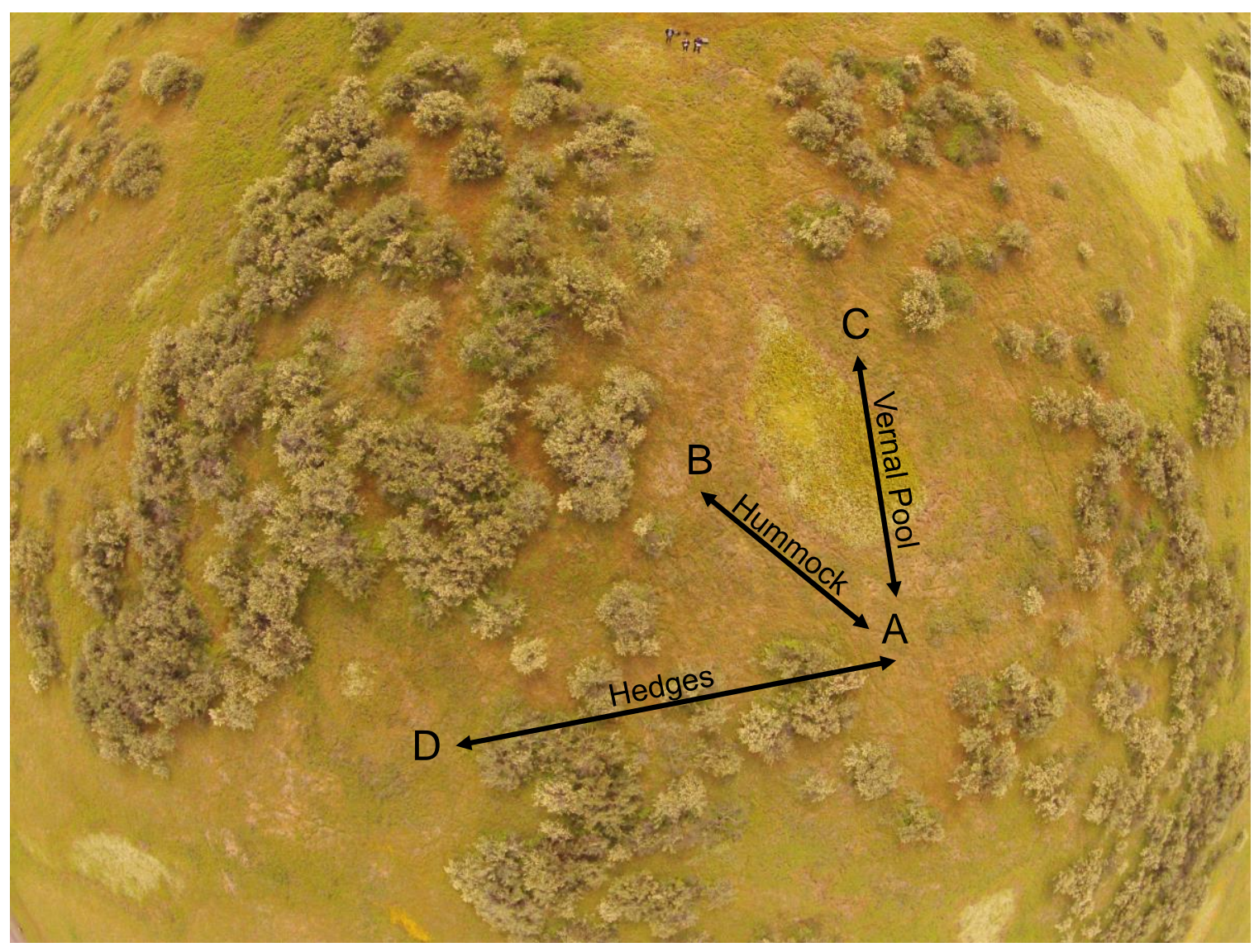

Fig. 4: General sampling design for each cluster. Letters A-D indicate sampling sites.

\section{Genetic Analysis}

I isolated DNA following the Qiagen DNeasy 96 Plant Kit procedure for frozen plant tissue (Qiagen, Redwood City, CA), with a 100 ul elution instead of 200 ul to maximize DNA concentration. The results of DNA extraction were quantified using a Qubit 3.0 Fluorometer (Thermo Fisher Scientific, Waltham, MA). Following DNA extraction, samples from each collection site $(n=20)$ were pooled, with each sample contributing an equimolar amount of DNA, totaling 32 pools containing 20 samples each (Stull et al., 2013). 
I sequenced both single-sample libraries (two per cluster; 16 total) and pooled libraries (one for every site; 32 total) to estimate haplotype frequencies in each pool. Libraries were prepared using the Kapa HyperPlus kit for Illumina ${ }^{\circledR}$ (Kapa Biosystems Inc., Wilmington, MA). The procedure was altered to use NEBNext@ Dual Index Primers (New England BioLabs Inc., Ipswich, MA) instead of primers provided by Kapa due to troubleshooting problems with the original kit. The enzymatic fragmentation and amplification of samples were performed on an Eppendorf Mastercycler Nexus Gradient thermal cycler (Eppendorf, Hauppauge, NY) with 6 cycles of amplification. The Qubit ${ }^{\mathrm{TM}}$ 3.0 Fluorometer was used as a preliminary quality check for DNA libraries, where libraries with at least $100 \mathrm{ng}$ of output DNA were considered successful.

For chloroplast target enrichment, I multiplexed single sample and pooled libraries by combining equal amounts of DNA from each library based on its DNA concentration. I used a custom MYcroarray MYbaits target enrichment kit (MYcroarray, Ann Arbor, MI) designed for chloroplast genome capture (Kohrn and Cruzan in preparation). The custom capture array was designed with a taxonomically diverse set of 24 chloroplast reference genomes, similar to the procedure described in Stull et al. (2013). The custom baits included the reference cpDNA genomes of Cryptantha torreyana and Salvia miltiorrhiza, species that are closely related to $P$. nothofulvus. After chloroplast capture, the enriched libraries were sent to the Oregon Health and Sciences University (OHSU) Massively Parallel Sequencing Shared Resource (MPSSR) where samples were quality checked using an Agilent 2200 TapeStation (Agilent Technologies, Santa Clara, CA), and subsequently sequenced on an Illumina ${ }^{\circledR}$ HiSeq 2500 sequencer (Illumina Inc., San Diego, CA). 
I assembled a de novo P. nothofulvus chloroplast genome using a high-quality individual from sequencing using BWA (version 0.7.12). S. miltiorrhiza was chosen as a reference for $P$. nothofulvus over $C$. torreyana because the former was more complete.. Reads were aligned to the reference using the BWA MEM algorithm (Li, 2013), and unmapped reads were filtered using Samtools 1.3.1 ( $\mathrm{Li}$ et al. 2009). A fastq file of the preprocessed sample was generated using the PicardTools SamToFastq (Picard 2017) (version 2.9.0) Scaffolds were then generated by the SPAdes Genome Assembler version 3.6.2 (Nurk et al. 2013). The S. miltiorrhiza reference was queried against the resulting scaffolds in NCBI BLAST sequence analysis tool using the blastn algorithm for somewhat similar sequences (Johnson et al. 2008). P. nothofulvus scaffolds were manually sorted by position relative to the query in BLAST, and nodes shorter than 200 reads were discarded. Nodes were assembled in relation to the reference, and reverse compliment reads were adjusted as needed. After combination of overlapping reads, any remaining gaps were replaced with Ns.

Adapter sequences were trimmed using CutAdapt 1.13 (Martin, 2011), and lowquality base pairs were trimmed using Sickle (Joshi \& Fass, 2011). Trimmed sequencing results were aligned to the de novo P. nothofulvus chloroplast genome using BWA-MEM 0.7.15 (Li, 2013). The sequence was re-aligned around indels using Picard Tools 2.9.0 (Picard 2017). Single Nucleotide Polymorphisms (SNPs) were discovered using FreeBayes 1.0.2 (Garrison \& Marth, 2012) with a filtering depth of 500 base pairs using a custom python script. Single-sample libraries were used to reconstruct a network phylogeny and haplotypes were recovered from pooled SNP data using the program CallHap (Kohrn \& Cruzan, in preparation). This program creates a preliminary 
phylogeny using haplotypes generated from single sample libraries, discovers novel haplotypes, and estimates haplotype frequencies from pooled libraries using a linear regression method. The frequency of haplotypes found in each pool was then used to generate pairwise Edwards' chord genetic distances using the R-package Adegenet (Jombart, 2008; Jombart \& Ahmed, 2011).

\section{UAV Surveys and Circuit Resistance Maps}

To accurately classify specific environmental features that may be influencing seed dispersal, I performed an aerial survey of the entire prairie using a DJI Phantom 2 Vision+ drone mounted with an HD camera (Cruzan et al., 2016). The overall survey design was a series of 400 meter longitudinal transects, evenly spaced at every 15 meters across the northernmost $400 \times 400$ meters of Whetstone prairie, with images captured approximately every 15 meters along each transect from 40 meters in elevation.

Drone images were processed using Agisoft Photoscan software (Agisoft LLC, St. Petersburg, Russia) to conduct fisheye distortion corrections for each of the 457 aerial images captured by the drone before stitching them together to create an orthomosaic and Digital Surface Model (DSM; Fig. 5). These layers were imported into ArcMap (Release 10; ESRI - Environmental Systems Research Institute, Redlands, CA) and reprojected to the North American Datum (NAD) 1983 Universal Transverse Mercator (UTM) Zone 10 projection. I combined both the orthomosaic and DSM layers at 50\% transparency to ensure that discrete habitat types could be classified with greater confidence than using either layer on its own. Polygons were created using the Editor tool in ArcMap, with a streaming tolerance of 1 map unit (1 meter). For this classification, I pooled shrub and tree habitat, and isolated this vegetation type from hummock and swale (Fig. 2A). For all 
resistance surfaces (see below), I assigned a cell size of $0.8075 \mathrm{~m}^{2}$ to the raster layer before using it to generate a current map in Circuitscape 4.0.5 (McRae, Dickson, Keitt, \& Shah, 2008). For this resistance surface, dry prairie hummocks were assigned a resistance of one, vernal pools a resistance of two, and C. cuneatus hedges a resistance of three, based on ecological observations. 

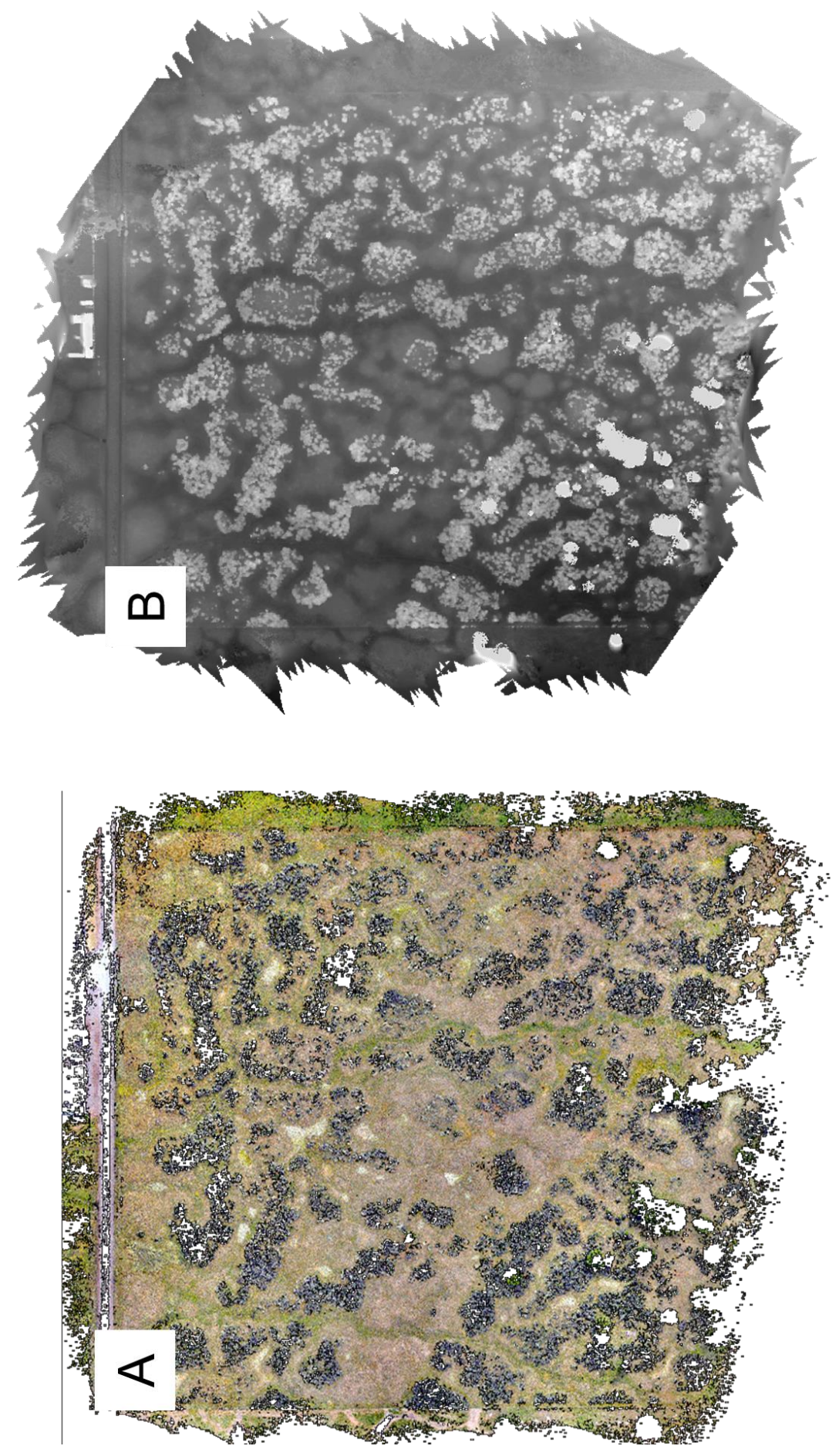

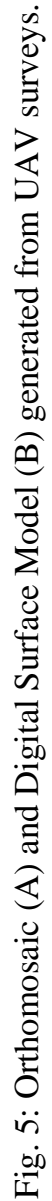


A separate layer for vole trails was generated using visual analysis of the orthomosaic described above as well as Google Earth satellite images from 4 July 2014 and 20 July 2010. The Google Earth images were chosen based on clarity and how well they complemented the drone orthomosaic, often showing more distinctive trails probably due to seasonal variation. The Google Earth images were georeferenced to the drone orthomosaic assess accuracy. Polyline shapefiles were created in ArcGIS and vole runways were traced with a final layer of runways connecting runway endpoints that pointed toward one another and containing probable runway lines. The final runway map was then given a buffer of 0.5 meters in ArcGIS to more accurately reflect their size in the prairie (Fig. 2B). For this resistance surface, I assigned vole runways a resistance of one, and non-vole runway areas a resistance of ten, based on ecological observations, before using this layer to generate a current map in Circuitscape 4.0.5 (McRae et al., 2008). I also conducted LCP analysis using the same vole runway resistance raster in the R-package gdistance (van Etten, 2012), because voles may represent a type of directed dispersal in which LCP may be a more robust test of landscape resistance.

I quantified flower density of $P$. nothofulvus across the entire prairie using image analysis of the orthomosaic (Fig. 5A) with a custom Python script (Cruzan et al., 2016). The script searched the entire orthomosaic for pixel values of a designated color range specific to $P$. nothofulvus flowers. To reduce noise from non-target species, only designated hummock habitats were included in the analysis, excluding bushes and vernal pools. The $P$. nothofulvus color range was determined by averaging the HSV values of 10x10 pixel selections of flower patches on the orthomosaic. Pixels outside the defined range were converted to black with a value of zero. The filtered image was exported in 
TIF format. In ArcGIS, the flower pixels were given a buffer of 0.5 meters to more accurately represent the clustered effect of flower density in real space (Fig. 2C). For this resistance surface, I assigned flower pixels a resistance of one, and non-flower pixel areas a resistance of ten, based on ecological observations, before using it to generate a current map in Circuitscape 4.0.5 (McRae et al., 2008).

To test for interactions between environmental variables, I also created resistance raster layers that integrated the distribution of each combination of two variables (habitat and vole runways, habitat and flower density, vole runways and flower density). For habitat and vole runway interactions, I assigned patches of $C$. cuneatus bushes a resistance of four, swales a resistance of three, hummocks a resistance of two, and vole runways a resistance of one. For habitat and flower density interactions, I assigned the habitat features the same resistances as the previous resistance raster, and assigned the flower pixels a resistance of one. For vole runway and flower density interactions, I assigned non-runway/flower areas a resistance of ten, vole runways a resistance of five, and flower pixels a resistance of one. I then used these resistance rasters to generate current maps in Circuitscape 4.0.5(McRae et al., 2008).

Using the Circuitscape for ArcGIS toolbox, I generated current maps and pairwise current matrices for all three resistance surfaces: habitat, vole runways, and flower density. I used P. nothofulvus sampling locations as focal nodes, and generated pairwise current values between all pairs of focal nodes, based on eight neighbor connections. These parameters were used for all three environmental variables I investigated here, as well as for the interactions between them. Pairwise current matrices generated through Circuitscape were then used in statistical analysis and model selection. 
Dispersal Model Selection

I used multiple regression on distance matrices (MRDM) in the R-package Ecodist (Goslee \& Urban, 2007) as a method for analyzing my spatial ecological data (Blair, Arcos, de la Cruz, \& Murphy, 2013; Dudaniec, Spear, Richardson, \& Storfer, 2012; Rioux Paquette, Talbot, Garant, Mainguy, \& Pelletier, 2014; Selkoe et al., 2010). The MRDM function is derived from the Mantel test, and uses permutations to test for significant relationships between an indicator distance matrix (e.g. genetic distance), and one or more predictor matrices (e.g. environmental variables) (Legendre, Lapointe, \& Casgrain, 1994). Unlike Mantel tests, MRDM can model nonlinear and polynomial relationships. Here, I use MRDM in conjunction with Mantel tests, using 1000 permutations in both, to find the model that best explains how P. nothofulvus seeds are dispersing throughout Whetstone. I use simple and partial Mantel tests as a statistical comparison to MRDM to investigate if they show consistent patterns of significance in my data. To be sure that my predictor variables are not highly collinear, I calculated the Variance Inflation Factor (VIF) for each predictor, where predictors with a VIF greater than ten are dropped from the model (Craney \& Surles, 2002).

The pairwise current matrices for my six predictor variables (three environmental variables and three interactions) generated from Circuitscape acted as predictor variables in MRDM and Mantel tests, with a pairwise geographic distance matrix as the null hypothesis predictor. I used a pairwise Edwards' chord $D$ matrix generated using the Adegenet R-package, described earlier, as the response variable in all models. To find the model that best explains gene flow, I started by including all three predictor variables 
- habitat type, vole runways, and flower density - in MRDM and Mantel tests, and further optimized the model by excluding each variable independently to see if the model improved or worsened. I then generated models reflecting interactions between variables using the three interaction matrices as independent predictor variables. I also tested for quadratic relationships in model selection by squaring each non-interactive predictor variable matrix and including squared matrices as new predictor variables. Additionally, I tested the predictive strength of LCP using the pairwise distance matrix generated from LCP analysis, described earlier, as a predictor variable. In all models, I corrected for geographic distance by including a geographic distance matrix as a predictor variable (Muñoz-Pajares et al., 2016). To ensure parsimony in model selection, all combinations of explanatory variables were tested and irrelevant variables were excluded using a backward selection procedure (Murtaugh, 2009; Rioux Paquette et al., 2014). Although Akaike information criterion (AIC) values are often used when selecting regression variables for a model, it is not appropriate for MRDM analysis because AIC assumes independence between data points. The matrices used in this MRDM analysis include pairwise genetic distances that are non-independent by nature; therefore, AIC cannot be used as a criterion for model selection (Goldberg \& Waits, 2010; Rioux Paquette et al., 2014). Instead, the model(s) that explain(s) the most variation (highest $\mathrm{R}^{2}$ value) while also being significant $(\mathrm{p}<0.05)$ will show which, if any, environmental variables are influencing seed dispersal. 
Results

Haplotype Genetic Structure

Single nucleotide polymorphism (SNP) frequencies for all 32 site samples of $P$. nothofulvus revealed nine unique haplotypes present within the Whetstone Prairie Reserve (Fig. 6). Five haplotypes were generated from single sample libraries and four new haplotypes were discovered using the CallHap pipeline (Kohrn \& Cruzan 2017, in preparation). These haplotypes varied in frequency from 5\% (one out of 20 individuals sampled) to $100 \%$. Haplotype two was most common throughout the prairie, where nine populations were characterized by only this single haplotype. Haplotypes displayed strong genetic structure throughout the prairie, suggesting limited seed dispersal in $P$. nothofulvus. Across all populations, the Residual Sum of Squares (RSS) for SNP frequency estimates were less than the value corresponding to the frequency of a single individual (5\%), indicating high confidence. 


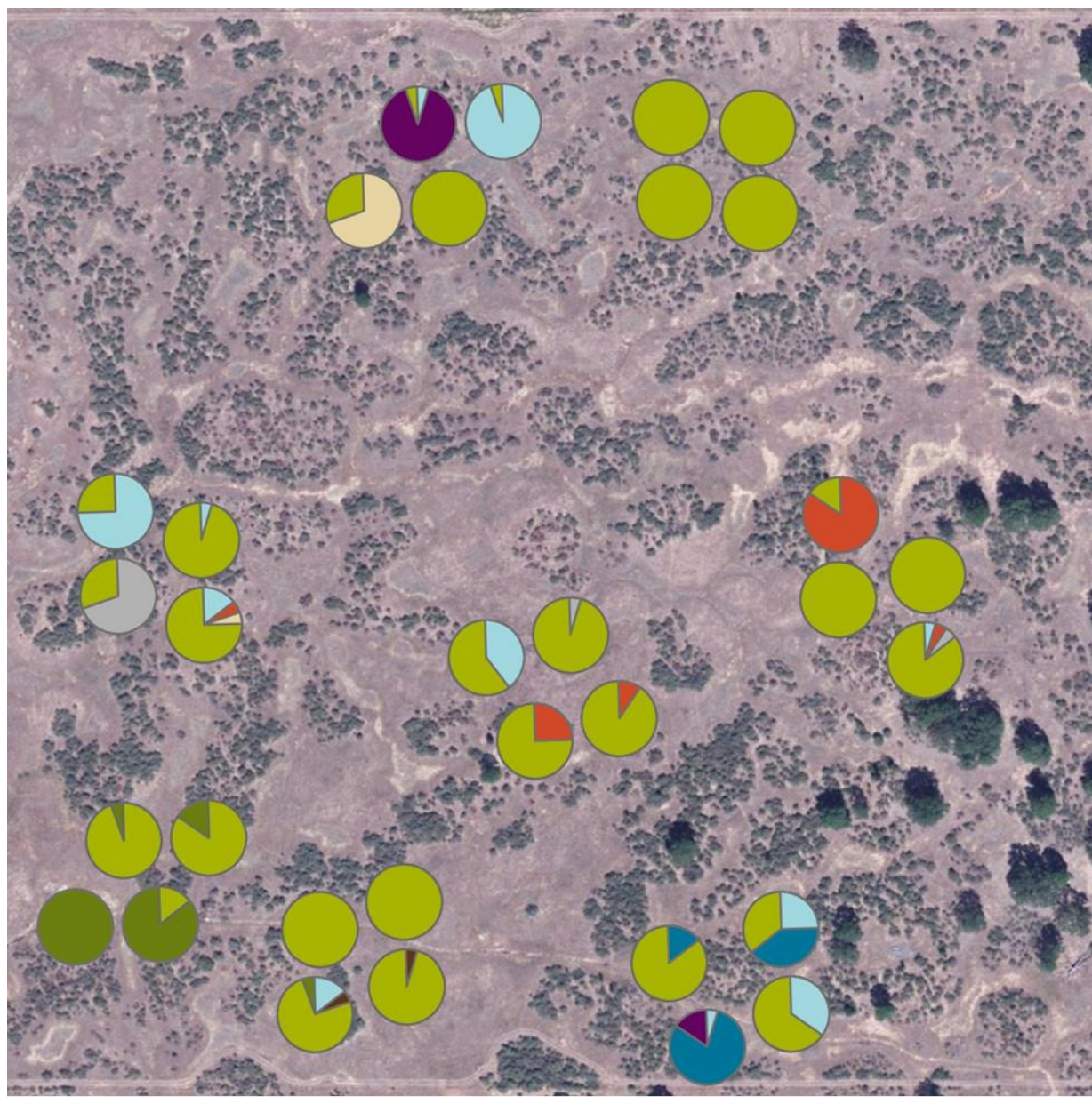

몽

के एٕ:

$\vec{\omega} \vec{\omega} \vec{\omega} \vec{\omega} \vec{\omega}$

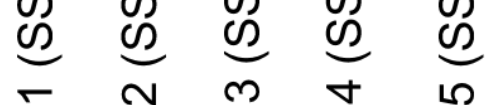

$1 \wedge \infty$

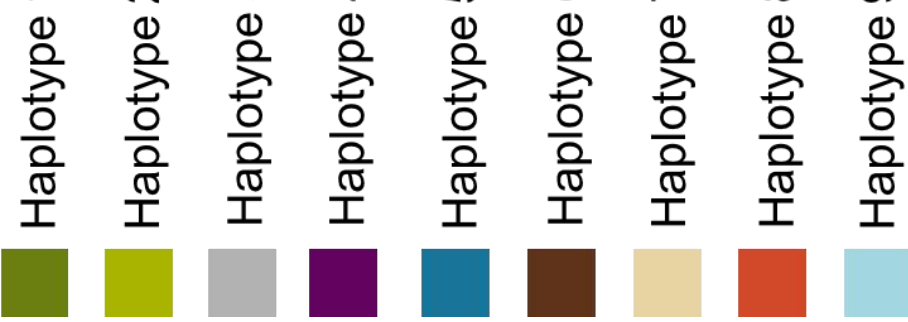

क क

莺

苞

.

品

空员

공

空 है

$\ddot{0}$ 응

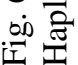


I generated a pairwise genetic distance matrix using Edwards' chord distance $(D)$ (Appendix A). The Edwards' distance was chosen over other genetic distance measures because it incorporates phylogenetic relatedness in its distance calculation, and can distinguish between genetically similar populations more easily than other common genetic distance measures (Libiger, Nievergelt, \& Schork, 2009). This is an important distinction in this study because the haplotype structure I found in these populations suggests higher relatedness within sites. The genetic distance matrix was then used as the response variable in MRDM model development. I also used the genetic distance matrix to find relatedness within and among the eight sampling clusters by finding the average distance within and among clusters, and compared those average values to the average distance of all pairwise genetic distances (Table 1). My analysis showed that within clusters, average distances ranged from zero (where all samples were characterized by a single haplotype) to 0.645 , with an average distance among clusters of 0.348 . By comparison, the average of all pairwise distances was 0.53 . Because genetic distance within clusters was, on average, lower than that of all pairwise distances, there is evidence for strong genetic structure within Whetstone. 
Table 1: Average genetic distance (D) within and among clusters. Note that the average $D$ within clusters is, on average, lower than that of all pairwise connections, indicating strong genetic structure of $P$. nothofulvus within the Whetstone prairie.

\begin{tabular}{|c|c|c|}
\hline Sampling Cluster & Average $D$ within clusters & Standard error \\
\hline 1 & 0.406 & 0.085 \\
\hline 2 & 0.446 & 0.079 \\
\hline 3 & 0.645 & 0.098 \\
\hline 4 & 0 & 0 \\
\hline 5 & 0.172 & 0.040 \\
\hline 6 & 0.469 & 0.081 \\
\hline 7 & 0.299 & 0.056 \\
\hline 8 & 0.348 & 0.084 \\
\hline $\begin{array}{c}\text { Average of within-cluster } \\
\text { averages }\end{array}$ & 0.348 & 0.123 \\
\hline $\begin{array}{l}\text { Average of all pairwise } \\
\text { distances }\end{array}$ & 0.530 & \\
\hline
\end{tabular}




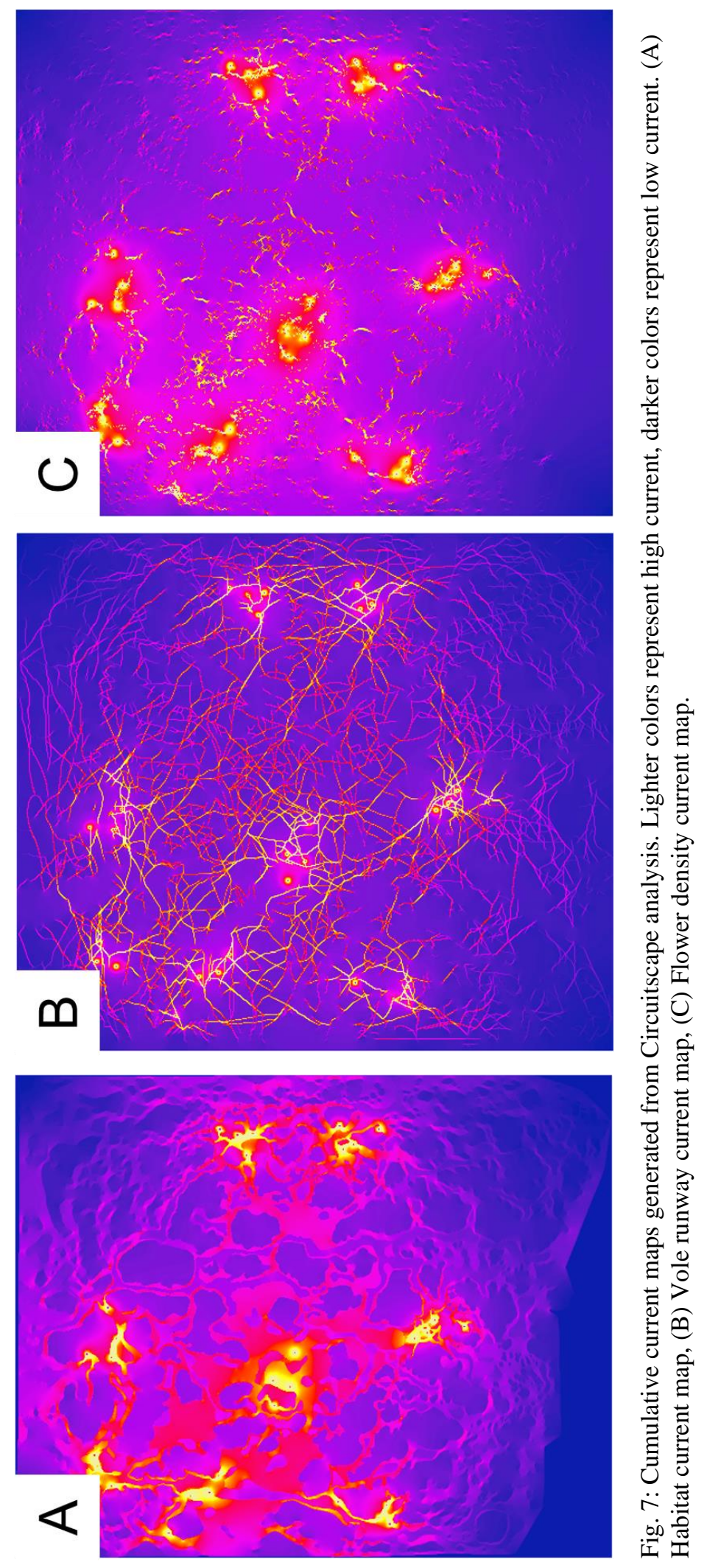




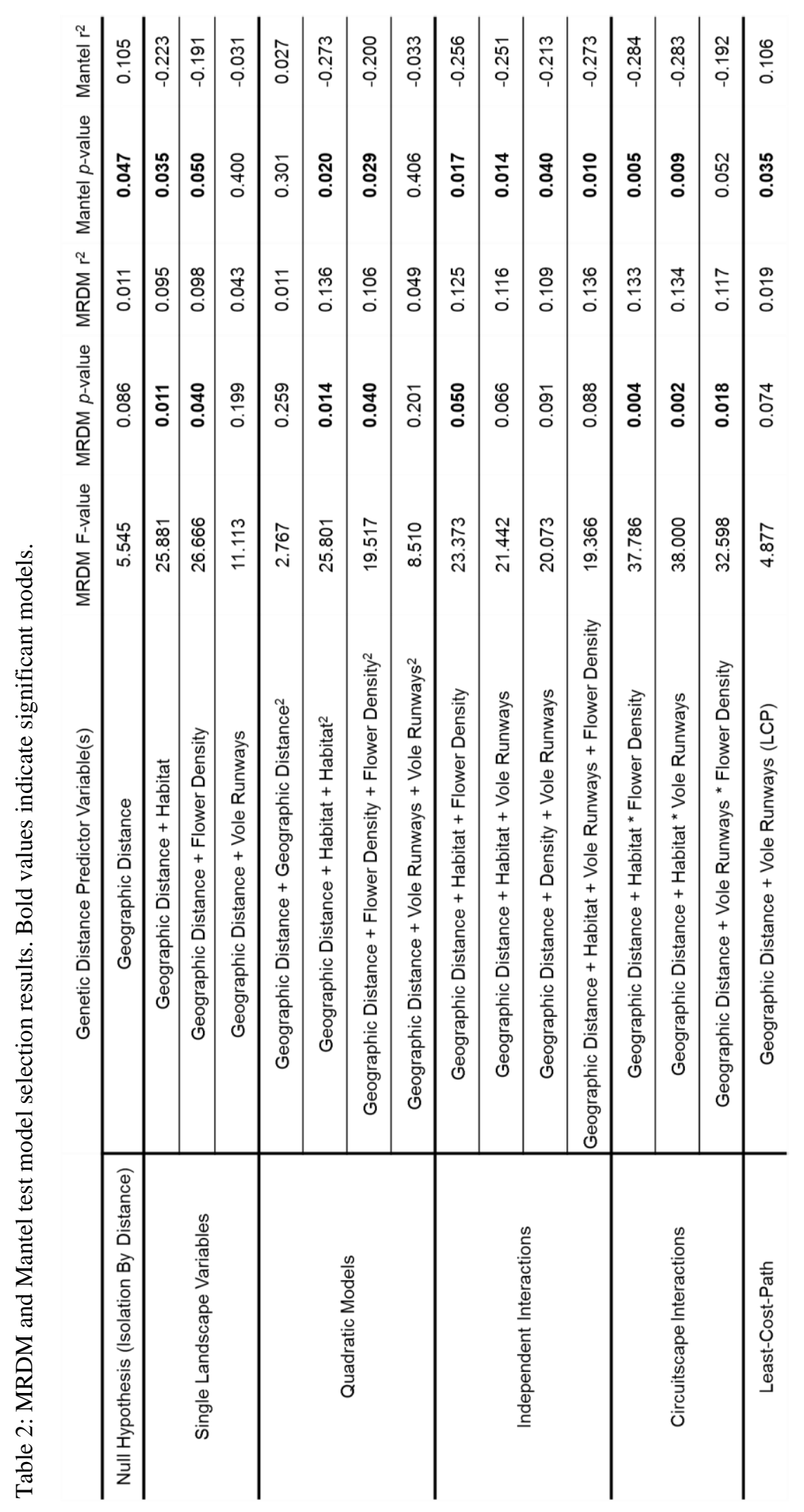


Dispersal Models

Pairwise current matrices and current maps (Fig. 7) for my three predictor variables (habitat type, vole runways, and flower density), as well as interaction variables (habitat and vole runways, habitat and flower density, vole runways and flower density) were generated through Circuitscape. These six pairwise current matrices and quadratic variable matrices were used as predictors in MRDM model development. Appendices B$\mathrm{H}$ include pairwise current matrices for habitat type, vole runways, flower density, and interactions between them. Appendix I includes pairwise LCP distances for vole runways, generated separately (see methods).

Although MRDM and Mantel tests provided competing results in model selection, there were some general patterns observed (Table 2). Overall, MRDM provided more conservative estimates of model significance. I only found significant evidence of IBD using a simple Mantel test, while MRDM did not support geographic distance as a predictor of genetic distance. I also found evidence that interaction variables, where I combined two variables in Circuitscape resistance surfaces, were generally the best predictors of genetic distance, suggesting that environmental variables are not working in isolation when it comes to dispersal in P. nothofulvus. There was also a general pattern in MRDM where models including habitat type as a predictor variable were most significant, flower density less significant, and vole runways least significant. In fact, vole runways were a significant predictor in MRDM only when included in interaction variables with habitat type and flower density, suggesting that their overall contribution 
to dispersal is minimal. Models showing quadratic relationships for habitat type and flower density were significant in MRDM, however, they did not perform better than models showing a linear relationship for habitat type and flower density.

Mantel tests, like MRDM, showed that the interaction variables including habitat type were the best predictors of genetic distance, but the remaining results were not consistent with the MRDM results. The results of partial Mantel tests highlighted the importance of independent interactions between variables, where the model including all three environmental variables independently was third most significant, and the next most significant models include independent interactions of vole runways and flower density with habitat type. Despite the significance of these independent interactions, they are still much less significant than the models including interactions between them, which again illustrates that environmental variables do not act in isolation to influence gene flow. In Mantel tests, quadratic models were a significant predictor of genetic distance, however, they did not perform significantly better than their linear counterparts. Like MRDM, Mantel tests suggested that vole runways were not a significant predictor of genetic distance in both linear and quadratic models, however, the model including LCP analysis of vole runways was significant, indicating that there may be some form of directed dispersal along vole runways playing a role in gene flow. 


\section{Discussion}

My analyses indicate that seed dispersal in P. nothofulvus is largely influenced by landscape features. Although I found some evidence for IBD, environmental variables had a much stronger influence on seed dispersal than geographic distance. These results indicate that genetic structure can be best explained by interactions between variables, where the lowest resistance to dispersal is on hummocks in areas transected by vole runways and in areas with high flower density. These interactions also highlight how the mosaic of habitat types within Whetstone determine genetic structure, where dispersal in $P$. nothofulvus is very strongly associated with dry hummock habitat. My results suggest that vole runways play a minimal role in dispersal when considered in isolation, but may represent some form of secondary directed dispersal by small mammals - especially if the habitat matrix is considered. Generally, habitat type was the strongest influence on $P$. nothofulvus seed dispersal within Whetstone, especially when paired with other variables.

The results of the MRDM and Mantel tests results coincided to highlight the importance of the habitat mosaic within Whetstone for $P$. nothofulvus seed dispersal. The strong genetic structure of $P$. nothofulvus within Whetstone suggests that there is limited seed dispersal in this species, which may be why habitat type is generally the best predictor of genetic distance in my dispersal models, especially if most seeds are being deposited on hummocks of dry prairie. This species may be experiencing habitat-specific dispersal, where a disproportionate number of seeds fall on favorable habitat, which then results in the spatial distribution and genetic structure of populations that I observe here. Habitat suitability may be the most important factor in seed dispersal and seedling survival (Schupp, 1995); if most seeds of P. nothofulvus are dispersed in suitable habitat, 
there would be little selective pressure for mechanisms to disperse greater distances. This is especially true in heterogeneous environments, where environmental quality declines abruptly outside of suitable habitat (Baythavong, Stanton, \& Rice, 2009). I observe this type of environmental heterogeneity in the Whetstone vernal pool complex, which may explain why P. nothofulvus dispersal is so strongly habitat-dependent. The close association between $P$. nothofulvus and hummock habitat in the vernal pool mosaic may also represent an adaptive barrier to dispersal across other habitats within Whetstone.

Additionally, the influence of flower density on dispersal may represent the effect of annual plant turnover facilitating local dispersal. Because seedlings of $P$. nothofulvus do not have to compete for space with older plants, there is little pressure for seeds to disperse beyond their parent plant, especially if parent plants are responding to microhabitat requirements within hummocks of dry prairie. If one considers how a perennial species would respond to the same scenario, competition between seedlings and established plants may result in increased mortality of seedlings and greater selective pressure for dispersal beyond established patches. A study of two perennial bushes (Calluna vulgaris and Erica cinerea) found that established plants acted as seed traps, concentrating seed deposition close to parent plants (Bullock \& Moy, 2004). In these perennial species, seeds have lower rates of establishment and survival in closed vegetation than in open areas, suggesting that this type of seed trapping results in decreased fitness for seedlings. This may not be the case for annual species, where parent plants do not pose a competitive threat for their progeny. In studies of dispersal in two different annual species (Vulpia fasciculata and Lepidium campestre), there was a strong correlation between dense patches of parent plants and reduced dispersal distances, 
although in these species there was little evidence of reduction in progeny fitness because of reduced dispersal (Thiede \& Augspurger, 1996; Watkinson, 1978).

Although my results indicate that vole runways do not play a large role in seed dispersal, the significance of the LCP analysis indicates that there may be some form of directed dispersal along vole runways. As discussed earlier, LCP analysis shows only the single best route option in resistance modeling, and has been shown to outperform Circuitscape in cases where individuals are dispersing along established routes (McClure et al., 2016). If vole runways are influencing dispersal in $P$. nothofulvus, it is likely due to the role that small mammals play in dispersal along the runways. These runways may represent a form of secondary directed dispersal, where seeds may fall onto the trail and are then eaten, stick to fur, or simply get pushed along the runway by the movement of small mammals. The California vole has a home range $\left(85 \mathrm{~m}^{2}\right.$; (Heske, 1987)) well within the area that I am investigating $\left(1600 \mathrm{~m}^{2}\right)$, which indicates that if vole movement is responsible for some portion of dispersal, then those dispersal events would be detectable in this study. Similarly, a study investigating spatial patch dynamics of an annual grassland found that disturbance from gopher movement contributed significantly to the spatial distribution of plants at the landscape level (Wu \& Levin, 1994). In this study, seeds may be dispersed along the runways by other small mammals that have been observed in Whetstone (Frank, Barry, Madden, \& Southworth, 2008), namely deer mice (Peromyscus maniculatus) and western harvest mice (Reithrodontomys megalotis).

I found evidence that vole runways may be facilitating dispersal in conjunction with habitat type, where runways transecting hummocks confer the lowest resistance to dispersal. This is probably due to the presence of vernal pools obstructing dispersal in 
swales, forcing small mammals to navigate along runways on hummocks of dry prairie. Examination of Google Earth satellite images dating back to the early 1990s indicates that these runways are apparently stable over long enough time frames to have significant effects on population genetic structure in this species.

The strong genetic structure I found across this relatively fine spatial scale suggests extremely limited seed dispersal in $P$. nothofulvus. Variation in haplotype frequencies among sites could be due solely to the influences of gene flow and genetic drift, but may also develop if dispersal is infrequent enough to reduce the spread of new mutations, which my data suggest. Normally, high relatedness due to mutation among local sampling sites is observed over a scale of several kilometers. Surprisingly, I observe this phenomenon at the scale of tens of meters in $P$. nothofulvus. Although the strong relatedness within sites can be partially explained by lower effective population size due to the haploid nature of cpDNA (C. Birky, Fuerst, \& Maruyama, 1989), this does not fully explain why haplotypes are not evenly distributed across all populations. Mutations arise locally and accumulate due to drift, but are not spread across populations because of limited seed dispersal in $P$. nothofulvus.

Despite limited dispersal in $P$. nothofulvus, I found that several haplotypes were present at opposite ends of the prairie. The chance of these haplotypes appearing in these sites as a consequence of parallel mutations is extremely unlikely; it is more probable that their presence is due to rare long-distance dispersal events, probably from secondary dispersal vectors such as small mammals, birds, or ungulates. Birds and ungulates, such as western meadowlark (Sturnella neglecta), Savannah sparrow (Passerculus sandwichensis), elk (Cervus canadensis), and deer (Odocoileus sp.), have been observed 
in Rogue Valley prairies (Friedman, 2010), and may be contributing to secondary dispersal. Long distance seed movement would not necessarily occur along vole runways, and thus would not be detectable using the methods I use here. Birds and ungulates have much larger home ranges than voles, and have the potential to serve as vectors for seed movement over much greater distances, resulting in rare long-distance dispersal events within and among prairie fragments.

The results of this study generally agree with the existing literature concerning landscape genetics and fine-scale seed dispersal. I found that habitat features, including C. cuneatus hedges, impede dispersal at a fine-scale. Similarly, a 2013 study found that on the order of a few meters, patches of shrub (Sarcopoterium spinosum) modified seed movement of herbaceous plants, contributing to fine-scale patterns of seed dispersal (Giladi, Segoli, \& Ungar, 2013). However, this study measured seed rain rather than cpDNA variation to investigate the effect of fine-scale landscape features on dispersal. Most other studies on fine-scale seed dispersal using genetic techniques focus on a geographic range much greater than the small prairie I investigated here, due to lack of adequate variation at smaller scales to resolve the effect of landscape features on dispersal. For example, a landscape genetics study of a herbaceous plant (Erysimum mediohispanicum) investigated drivers of gene flow at multiple spatial scales, where finescale sites were separated by a few kilometers, rather than a few meters, and found that topographic variation (IBR) was a significant driver of genetic structure at this scale (Muñoz-Pajares et al., 2016). Similarly, a study of dispersal in wax palm (Ceroxylon echinulatum) investigated contemporary gene flow due to seed dispersal, and found a significant effect of landscape features (e.g. elevation, habitat suitability) on fine-scale 
seed dispersal (on the order of a few kilometers) (Trénel et al. 2008). Although these studies define fine-scale dispersal much more broadly than my investigation, they still find a significant effect of landscape features on gene flow. The appropriate scale of sampling is largely determined by the level of spatial genetic structure and life history of the focal species. Anderson et al. (2010) outline some considerations for landscape genetic studies, highlighting that as separation between sampling sites changes, different landscape features will be introduced as potential influencers of gene flow. Separating sites by many potential barriers to dispersal may make it difficult to determine the influence of specific landscape features on gene flow, however, sampling at larger scales may reveal new factors influencing gene flow (e.g. mutation, historical dispersal). To fully understand drivers of genetic variation due to seed dispersal, multiple spatial scales should be considered. 


\section{Conclusions}

The processes and mechanisms responsible for seed dispersal and gene flow at a fine spatial scale are elusive and difficult to quantify. However, using whole-genome cpDNA variation, I can resolve genetic structure at a scale that was once thought only possible using direct field observation methods. My investigation revealed that dispersal at this fine-scale is intrinsically tied to the landscape; this is especially evident in the complex heterogeneous landscape that characterizes Whetstone Savanna Preserve. I found evidence that IBD does not explain dispersal in $P$. nothofulvus. Instead, dispersal and gene flow can be primarily explained by habitat preference in this species, which may be considered a habitat specialist in this prairie. The annual life history of $P$. nothofulvus is also an important factor in its dispersal; progeny respond to microhabitat requirements of the species and are not selectively pressured to colonize new habitats due to lack of competition with parent plants. In addition, seeds may be secondarily dispersed in a directed pattern along vole runways by small mammals. Other secondary dispersal vectors, such as birds and ungulates, may also be dispersing seeds at larger distances. These biotic patterns are a lesser influence on dispersal, but important nonetheless because they potentially allow for adaptations to spread across the prairie and over longer distances for the colonization of new habitats. This investigation reveals the potential for future studies to explore dispersal at a fine-scale and glean insights about the processes and mechanisms that govern seed dispersal across a range of spatial scales. 


\section{References}

Anderson, C. D., Epperson, B. K., Fortin, M. J., Holderegger, R., James, P. M., Rosenberg, M. S., ... Spear, S. (2010). Considering spatial and temporal scale in landscape-genetic studies of gene flow. Mol Ecol, 19(17), 3565-3575. doi:10.1111/j.1365-294X.2010.04757.x

Andrew, R. L., Ostevik, K. L., Ebert, D. P., \& Rieseberg, L. H. (2012). Adaptation with gene flow across the landscape in a dune sunflower. Mol Ecol, 21(9), 2078-2091. doi:10.1111/j.1365-294X.2012.05454.X

Antonovics, J., Thrall, P., Jarosz, A., \& Stratton, D. (1994). Ecological genetics of metapopulations: the Silene-Ustilago plant-pathogen system. Ecological genetics, 146-170.

Baythavong, B. S., Stanton, M. L., \& Rice, K. J. (2009). Understanding the consequences of seed dispersal in a heterogeneous environment. Ecology, 90(8), 2118-2128.

Birky, C., Fuerst, P., \& Maruyama, T. (1989). Organelle gene diversity under migration, mutation, and drift: equilibrium expectations, approach to equilibrium, effects of heteroplasmic cells, and comparison to nuclear genes. Genetics, 121(3), 613-627.

Birky, C. W. (1995). Uniparental inheritance of mitochondrial and chloroplast genes: mechanisms and evolution. Proceedings of the National Academy of Sciences, 92(25), 11331-11338.

Blair, C., Arcos, V. H. J., de la Cruz, F. R. M., \& Murphy, R. W. (2013). Landscape genetics of leaf-toed geckos in the tropical dry forest of Northern Mexico. PLoS one, 8(2), e57433.

Brown, M. J., \& Human, K. G. (1997). Effects of harvester ants on plant species distribution and abundance in a serpentine grassland. Oecologia, 112(2), 237-243.

Bullock, J. M., \& Moy, I. L. (2004). Plants as seed traps: inter-specific interference with dispersal. Acta Oecologica, 25(1), 35-41.

Cain, M. L., Milligan, B. G., \& Strand, A. E. (2000). Long-distance seed dispersal in plant populations. American Journal of Botany, 87(9), 1217-1227.

Craney, T. A., \& Surles, J. G. (2002). Model-dependent variance inflation factor cutoff values. Quality Engineering, 14(3), 391-403.

Cronn, R., Liston, A., Parks, M., Gernandt, D. S., Shen, R., \& Mockler, T. (2008). Multiplex sequencing of plant chloroplast genomes using Solexa sequencing-bysynthesis technology. Nucleic acids research, 36(19), e122-e122.

Cruzan, M. B., Weinstein, B. G., Grasty, M. R., Kohrn, B. F., Hendrickson, E. C., Arredondo, T. M., \& Thompson, P. G. (2016). Small unmanned aerial vehicles (micro-UAVs, drones) in plant ecology. Applications in Plant Sciences, 4(9), 1600041.

Dudaniec, R. Y., Spear, S. F., Richardson, J. S., \& Storfer, A. (2012). Current and historical drivers of landscape genetic structure differ in core and peripheral salamander populations. PLoS one, 7(5), e36769.

Dyer, R. J., Chan, D. M., Gardiakos, V. A., \& Meadows, C. A. (2012). Pollination graphs: quantifying pollen pool covariance networks and the influence of intervening landscape on genetic connectivity in the North American understory tree, Cornus florida L. Landscape ecology, 27(2), 239-251. 
Ellis, J. R., Bentley, K. E., \& McCauley, D. E. (2008). Detection of rare paternal chloroplast inheritance in controlled crosses of the endangered sunflower Helianthus verticillatus. Heredity, 100(6), 574-580.

Fant, J., Havens, K., Keller, J., Radosavljevic, A., \& Yates, E. (2014). The influence of contemporary and historic landscape features on the genetic structure of the sand dune endemic, Cirsium pitcheri (Asteraceae). Heredity, 112(5), 519-530.

Forget, P.-M., \& Milleron, T. (1991). Evidence for secondary seed dispersal by rodents in Panama. Oecologia, 87(4), 596-599.

Frank, J., Barry, S., Madden, J., \& Southworth, D. (2008). Oaks belowground: mycorrhizas, truffles, and small mammals.

Friedman, S. (2010) Recovery Plan for Rogue and Illinois Valley Vernal Pool and Wet Meadow Ecosystems.

Garant, D., Forde, S. E., \& Hendry, A. P. (2007). The multifarious effects of dispersal and gene flow on contemporary adaptation. Functional Ecology, 21(3), 434-443.

Garrison, E., \& Marth, G. (2012). Haplotype-based variant detection from short-read sequencing. arXiv preprint arXiv:1207.3907.

Giladi, I., Segoli, M., \& Ungar, E. D. (2013). Shrubs and herbaceous seed flow in a semi-arid landscape: dual functioning of shrubs as trap and barrier. Journal of Ecology, 101(1), 97-106.

Goldberg, C., \& Waits, L. (2010). Comparative landscape genetics of two pond-breeding amphibian species in a highly modified agricultural landscape. Molecular ecology, 19(17), 3650-3663.

Goslee, S. C., \& Urban, D. L. (2007). The ecodist package for dissimilarity-based analysis of ecological data. Journal of Statistical Software, 22(7), 1-19.

Gotelli, N. J., \& Simberloff, D. (1987). The distribution and abundance of tallgrass prairie plants: a test of the core-satellite hypothesis. The American Naturalist, $130(1), 18-35$.

Hanski, I. (1998). Metapopulation dynamics. Nature, 396(6706), 41-49.

Herrmann, J. D., Carlo, T. A., Brudvig, L. A., Damschen, E. I., Haddad, N. M., Levey, D. J., . . Tewksbury, J. J. (2016). Connectivity from a different perspective: comparing seed dispersal kernels in connected vs. unfragmented landscapes. Ecology, 97(5), 1274-1282.

Heske, E. J. (1987). Spatial structuring and dispersal in a high density population of the California vole Microtus californicus. Ecography, 10(2), 137-148.

Hoshizaki, K., Suzuki, W., \& Sasaki, S. (1997). Impacts of secondary seed dispersal and herbivory on seedling survival in Aesculus turbinata. Journal of Vegetation Science, 8(5), 735-742.

Howe, H. F., \& Smallwood, J. (1982). Ecology of seed dispersal. Annual review of ecology and systematics, 13(1), 201-228.

Hutchison, D. W., \& Templeton, A. R. (1999). Correlation of pairwise genetic and geographic distance measures: inferring the relative influences of gene flow and drift on the distribution of genetic variability. Evolution, 1898-1914.

Ingham, E., \& Wilson, M. (1999). The mycorrhizal colonization of six wetland plant species at sites differing in land use history. Mycorrhiza, 9(4), 233-235. 
Jensen, T. S., \& Nielsen, O. F. (1986). Rodents as seed dispersers in a heath-oak wood succession. Oecologia, 70(2), 214-221.

Johnson, M., Zaretskaya, I., Raytselis, Y., Merezhuk, Y., McGinnis, S., \& Madden, T. L. (2008). NCBI BLAST: a better web interface. Nucleic acids research, 36(suppl 2), W5-W9.

Jombart, T. (2008). adegenet: a R package for the multivariate analysis of genetic markers. Bioinformatics, 24(11), 1403-1405.

Jombart, T., \& Ahmed, I. (2011). adegenet 1.3-1: new tools for the analysis of genomewide SNP data. Bioinformatics, 27(21), 3070-3071.

Jordan, W. C., Courtney, M. W., \& Neigel, J. E. (1996). Low levels of intraspecific genetic variation at a rapidly evolving chloroplast DNA locus in North American duckweeds (Lemnaceae). American Journal of Botany, 430-439.

Joshi, N., \& Fass, J. (2011). Sickle: a sliding-window, adaptive, quality-based trimming tool for FastQ files. Available from: github. com/najoshi/sickle.

Legendre, P., Lapointe, F.-J., \& Casgrain, P. (1994). Modeling brain evolution from behavior: a permutational regression approach. Evolution, 1487-1499.

Li, H. (2013). Aligning sequence reads, clone sequences and assembly contigs with BWA-MEM. arXiv preprint arXiv:1303.3997.

Li, H., Handsaker, B., Wysoker, A., Fennell, T., Ruan, J., Homer, N., .. 1000 Genome Project Data Processing Subgroup. (2009). The Sequence Alignment/Map format and SAMtools. Bioinformatics, 25(16), 2078-

2079. http://doi.org/10.1093/bioinformatics/btp352

Libiger, O., Nievergelt, C. M., \& Schork, N. J. (2009). Comparison of genetic distance measures using human SNP genotype data. Human biology, 81(4), 389-406.

Manel, S., Schwartz, M. K., Luikart, G., \& Taberlet, P. (2003). Landscape genetics: combining landscape ecology and population genetics. Trends in ecology \& evolution, 18(4), 189-197.

Martin, M. (2011). Cutadapt removes adapter sequences from high-throughput sequencing reads. EMBnet. journal, 17(1), pp. 10-12.

Maskas, S. D., \& Cruzan, M. B. (2000). Patterns of intraspecific diversification in the Piriqueta caroliniana complex in southeastern North America and the Bahamas. Evolution, 54(3), 815-827.

McCauley, D. E. (1994). Contrasting the distribution of chloroplast DNA and allozyme polymorphism among local populations of Silene alba: implications for studies of gene flow in plants. Proceedings of the National Academy of Sciences, 91(17), 8127-8131.

McCauley, D. E. (1995). The use of chloroplast DNA polymorphism in studies of gene flow in plants. Trends in ecology \& evolution, 10(5), 198-202.

McClure, M. L., Hansen, A. J., \& Inman, R. M. (2016). Connecting models to movements: testing connectivity model predictions against empirical migration and dispersal data. Landscape ecology, 31(7), 1419-1432.

McRae, B. H., \& Beier, P. (2007). Circuit theory predicts gene flow in plant and animal populations. Proceedings of the National Academy of Sciences, 104(50), 1988519890. 
McRae, B. H., Dickson, B. G., Keitt, T. H., \& Shah, V. B. (2008). Using circuit theory to model connectivity in ecology, evolution, and conservation. Ecology, 89(10), 2712-2724.

McRae, B. H., \& Nürnberger, B. (2006). Isolation by resistance. Evolution, 60(8), 15511561.

Muñoz-Pajares, A., García, C., Abdelaziz, M., Bosch, J., Perfectti, F., \& Gómez, J. (2016). Drivers of genetic differentiation in a generalist insect-pollinated herb across spatial scales. Molecular ecology.

Murtaugh, P. A. (2009). Performance of several variable-selection methods applied to real ecological data. Ecology Letters, 12(10), 1061-1068.

Nathan, R., \& Muller-Landau, H. C. (2000). Spatial patterns of seed dispersal, their determinants and consequences for recruitment. Trends in ecology \& evolution, 15(7), 278-285.

Nurk, S., Bankevich, A., Antipov, D., Gurevich, A., Korobeynikov, A., Lapidus, A., ... \& Stepanauskas, R. (2013). Assembling genomes and mini-metagenomes from highly chimeric reads, p 158-170. In Research in computational molecular biology (Vol. 7821).

Ouborg, N., Piquot, Y., \& Van Groenendael, J. (1999). Population genetics, molecular markers and the study of dispersal in plants. Journal of Ecology, 87(4), 551-568.

Rioux Paquette, S., Talbot, B., Garant, D., Mainguy, J., \& Pelletier, F. (2014). Modelling the dispersal of the two main hosts of the raccoon rabies variant in heterogeneous environments with landscape genetics. Evolutionary applications, 7(7), 734-749.

Schupp, E. W. (1995). Seed-seedling conflicts, habitat choice, and patterns of plant recruitment. American Journal of Botany, 399-409.

Selkoe, K. A., Watson, J. R., White, C., Horin, T. B., Iacchei, M., Mitarai, S., . . Toonen, R. J. (2010). Taking the chaos out of genetic patchiness: seascape genetics reveals ecological and oceanographic drivers of genetic patterns in three temperate reef species. Molecular ecology, 19(17), 3708-3726.

Shah, V. B., \& McRae, B. (2008). Circuitscape: a tool for landscape ecology. Paper presented at the Proceedings of the 7th Python in Science Conference.

Slatkin, M. (1987). Gene flow and the geographic structure of natural populations. Science, 236, 787-793.

Stull, G. W., Moore, M. J., Mandala, V. S., Douglas, N. A., Kates, H.-R., Qi, X., . . Gitzendanner, M. A. (2013). A targeted enrichment strategy for massively parallel sequencing of angiosperm plastid genomes. Applications in Plant Sciences, 1(2), 1200497.

Taylor, S. M., \& Santelmann, M. V. (2014). Comparing Vegetation and Soils of Remnant and Restored Wetland Prairies in the Northern Willamette Valley. Northwest Science, 88(4), 329-343.

Thiede, D. A., \& Augspurger, C. K. (1996). Intraspecific variation in seed dispersion of Lepidium campestre (Barassicaceae). American Journal of Botany, 856-866.

Trénel, P., Hansen, M. M., Normand, S., \& Borchsenius, F. (2008). Landscape genetics, historical isolation and cross-Andean gene flow in the wax palm, Ceroxylon echinulatum (Arecaceae). Molecular Ecology, 17(15), 3528-3540. 
van Etten, J. (2012). R Package gdistance: Distances and Routes on Geographical Grids. Retrieved from

Vander Wall, S. B., Kuhn, K. M., \& Beck, M. J. (2005). Seed removal, seed predation, and secondary dispersal. Ecology, 86(3), 801-806.

Wang, B. C., \& Smith, T. B. (2002). Closing the seed dispersal loop. Trends in ecology \& evolution, 17(8), 379-386.

Watkinson, A. (1978). The demography of a sand dune annual: Vulpia fasciculata: III. The dispersal of seeds. The Journal of Ecology, 483-498.

Wenny, D. G. (2001). Advantages of seed dispersal: a re-evaluation of directed dispersal. Evolutionary Ecology Research, 3(1), 37-50.

Wright, S. (1943). Isolation by distance. Genetics, 28(2), 114.

Wu, J., \& Levin, S. A. (1994). A spatial patch dynamic modeling approach to pattern and process in an annual grassland. Ecological monographs, 64(4), 447-464.

Yu, H., Zhang, Y., Liu, L., Qi, W., Li, S., \& Hu, Z. (2015). Combining the least cost path method with population genetic data and species distribution models to identify landscape connectivity during the late Quaternary in Himalayan hemlock. Ecology and evolution, 5(24), 5781-5791.

Zhang, Q. (2010). Why does biparental plastid inheritance revive in angiosperms? Journal of plant research, 123(2), 201-206. 


\section{Appendix A}

Pairwise Edwards' chord genetic distance matrix

Supplemental file: "AppendixA_GeneticDistance.xlsx"

Size: $45 \mathrm{~KB}$

Required software: Microsoft Excel 


\section{Appendix B}

Pairwise geographic distance matrix

Supplemental file: "AppendixB_GeographicDistance.xlsx"

Size: $51 \mathrm{~KB}$

Required software: Microsoft Excel 


\section{Appendix C}

Pairwise habitat resistance matrix

Supplemental file: "AppendixC_HabitatResistance.xlsx"

Size: $50 \mathrm{~KB}$

Required software: Microsoft Excel 


\section{Appendix D}

Pairwise vole runway resistance matrix

Supplemental file: "AppendixD_RunwayResistance.xlsx"

Size: $51 \mathrm{~KB}$

Required software: Microsoft Excel 


\section{Appendix E}

Pairwise flower density resistance matrix

Supplemental file: “AppendixE_DensityResistance.xlsx"

Size: $51 \mathrm{~KB}$

Required software: Microsoft Excel 


\section{Appendix F}

Pairwise habitat/flower density resistance matrix

Supplemental file: "AppendixF_Habitat_Density.xlsx"

Size: $51 \mathrm{~KB}$

Required software: Microsoft Excel 


\section{Appendix G}

Pairwise habitat/vole runway resistance matrix

Supplemental file: "AppendixG_Habitat_Runways.xlsx"

Size: $51 \mathrm{~KB}$

Required software: Microsoft Excel 


\section{Appendix $\mathrm{H}$}

Pairwise vole runway/flower density resistance matrix

Supplemental file: "AppendixH_Runways_Density.xlsx"

Size: $52 \mathrm{~KB}$

Required software: Microsoft Excel 


\section{Appendix I}

Pairwise least-cost-path vole runway matrix

Supplemental file: "AppendixI_LCP_VoleRunways.xlsx"

Size: $49 \mathrm{~KB}$

Required software: Microsoft Excel 